\title{
Study protocol: a non-randomised community trial to evaluate the effectiveness of the communities that care prevention system in Germany
}

Dominik Röding $^{1 *} \mathbb{B}$, Renate Soellner ${ }^{2}$, Maren Reder ${ }^{2}$, Vera Birgel ${ }^{1}$, Constantin Kleiner $^{1}$, Maike Stolz ${ }^{1}$, Frederick Groeger-Roth ${ }^{3}$, Christian Krauth ${ }^{1}$ and Ulla Walter ${ }^{1}$

\begin{abstract}
Background: The Communities That Care (CTC) prevention planning and implementation system trains communities throughout a five-phase cycle to (1) build capacity for prevention, (2) adopt science-based prevention, (3) assess the prevention needs of adolescents living in the community, (4) select, and (5) implement evidencebased programs according to their needs. After CTC proved to be effective and cost-effective in the U.S., it is being used by an increasing number of communities in Germany. The aim of this study is to evaluate the effectiveness and cost-effectiveness of CTC in Germany.

Methods: Communities in CTC-phases 1 to $3(n=21)$ and individually-matched comparison communities $(n=21)$ were recruited for a non-randomised trial. To assess long-term outcomes, (1) a cohort of 5th Grade students will be surveyed biennially concerning behaviours (antisocial behaviour and substance use) and well-being as well as risk and protective factors. Additionally, (2) biennial cross-sectional surveys will be conducted in 6th, 8th, 10th, and 11th Grade in each community. To assess short-term outcomes, a cohort of ten key informants per community will be surveyed biennially concerning adoption of science-based prevention, collaboration, community support and community norms. (4) In a cross-sectional design, all ongoing prevention programs and activities in the communities will be assessed biennially and data will be collected about costs, implementation and other characteristics of the programs and activities. (5) To monitor the CTC implementation, the members of the local CTC-boards will be surveyed annually (cross-sectional design) about team functioning and coalition capacity. Data analysis will include general and generalised mixed models to assess the average treatment effect of CTC. Mediation analyses will be performed to test the logical model, e.g., adoption of science-based prevention as a mediator for the effectiveness of the CTC approach.
\end{abstract}

Discussion: This is the first controlled study to evaluate the effectiveness of a comprehensive community prevention approach in Germany. Evaluating the effectiveness of CTC in Germany is an important prerequisite for further diffusion of the CTC approach.

\footnotetext{
*Correspondence: roeding.dominik@mh-hannover.de

'Hannover Medical School, Institute for Epidemiology, Social Medicine and Health Systems Research, Hannover, Germany

Full list of author information is available at the end of the article
}

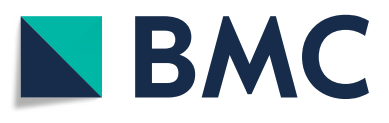

(C) The Author(s). 2021 Open Access This article is licensed under a Creative Commons Attribution 4.0 International License, which permits use, sharing, adaptation, distribution and reproduction in any medium or format, as long as you give appropriate credit to the original author(s) and the source, provide a link to the Creative Commons licence, and indicate if changes were made. The images or other third party material in this article are included in the article's Creative Commons licence, unless indicated otherwise in a credit line to the material. If material is not included in the article's Creative Commons licence and your intended use is not permitted by statutory regulation or exceeds the permitted use, you will need to obtain permission directly from the copyright holder. To view a copy of this licence, visit http://creativecommons.org/licenses/by/4.0/ The Creative Commons Public Domain Dedication waiver (http://creativecommons.org/publicdomain/zero/1.0/) applies to the data made available in this article, unless otherwise stated in a credit line to the data. 
Trial registration: This study was registered with German Clinical Trial Register: DRKS00022819 on Aug 18, 2021.

Keywords: Effectiveness, Non-randomised, Quasi-experimental, Community trial, Youth, Problem behaviour, Capacity building, Intersectoral collaboration, Risk factors, Protective factors

\section{Background}

Children and adolescent problem behaviour, such as antisocial behaviour, alcohol use, illicit drug use and delinquency, place a burden on healthy development and well-being [1-3]. Preventive programs aim to minimize these risk factors, strengthen corresponding protective factors, and promote resilience, which will be developed in a process of interaction between the individual and the environment [4-8]. In this context communities take a central function $[9,10]$. They have the opportunity to shape this in a targeted manner via various institutions and settings as well as the establishment of intersectoral collaborations. But communities often have a lack of knowledge regarding prevention and health promotion, so that in many cases prevention programs and strategies are selected and implemented that show no or only limited effectiveness $[11,12]$ or have not yet been evaluated. Lack of program fidelity is also a problem [13, 14].

Building community networks for prevention strengthens the implementation and coordination of prevention programs [15-17]. So far, there are only a few studies that have investigated their effect on the health of the target group and can show effects [18-20]. A program used worldwide to build such community networks for prevention is Communities That Care (CTC).

CTC was developed in the U.S. in the 1980s. It supports communities in establishing healthy environments that enable children and adolescents to grow up safely and healthy. The Community Youth Development Study (CYDS) showed that CTC increased the adoption of a science-based approach to prevention, sectorial collaboration for prevention, and community support for prevention [21] as well as the number of implemented evidence-based prevention programs and the number of program participants in the community [22]. This resulted in lower incidences in smoking cigarettes, smokeless tobacco use, alcohol use and delinquent behaviour (Odds Ratios 1.41 to 2.34) compared to control communities [23]. The effects of CTC on youth problem behaviours were fully mediated by community adoption of a science-based approach to prevention [24]. Economic evaluations indicated that CTC may produce a return on investment of approximately US\$10.23 for every dollar spent [25].

According to the CTC-model of community change it takes 1 year to observe improvements in throughputs, 2 years to observe effects in short-term outcomes and outputs, 3 years to observe mid-term outcomes and 5 years to observe long-term outcomes (Fig. 1). CTC's theory of change and results from Brown et al. [24] suggest that the community adoption of a science-based approach to prevention is the primary mechanism of CTC.

In 2009, CTC was transferred to Germany and has since been implemented in 33 communities. In this context, the database "Grüne Liste Prävention" (www. gruene-liste-praevention.de) has been developed, which includes German-language evidence-based prevention programs. A feasibility study in Lower Saxony showed the transferability (i.e., high level of acceptance and identification with the CTC approach in the model communities) of CTC to the German context [26, 27], but an evaluation of its effectiveness has not been conducted in Germany to date. The aim of this study is to evaluate the effectiveness and cost-effectiveness of CTC in Germany.

\section{Methods and design \\ Intervention \\ Intervention condition}

CTC implementation is organised into five phases [28]. Training in the various phases of the CTC process is provided by the CTC Training and Support Center (German Prevention Congress) to encourage communities to achieve milestones and benchmarks. Specially developed instruments support quality assurance and development. Figure 2 shows the objectives, activities, training and instruments for quality assurance in the respective phases.

\section{Comparison condition}

For the comparison communities, it was not examined whether they use an elaborated system of community prevention. Due to the international push of intersectoral community-based prevention approaches [29] through the WHO Ottawa Charter on Health Promotion [30] it can be assumed that the majority of these communities work with a local intersectoral network for prevention and health promotion. Böhm and Gehne [31] give an overview of such networks in Germany.

\section{Design}

A quasi-experimental study will be conducted in small towns, rural communities and districts of major cities in four German federal states (Baden-Württemberg, Bavaria, Lower Saxony, Rhineland-Palatinate) to evaluate the effectiveness of CTC in Germany; hereinafter 


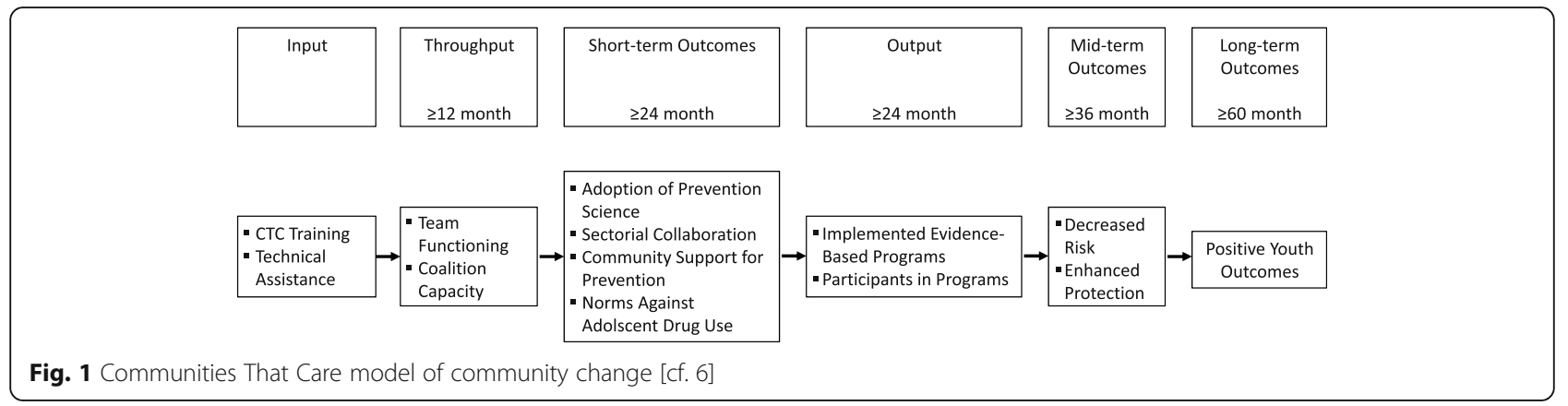

referred to as communities. The study is designed as a cluster non-randomised controlled trial [32]. To evaluate the effectiveness of CTC, data will be collected in a trend (repeated cross-sectional) and cohort design (Fig. 3). Additionally, the implementation of CTC will be evaluated (process evaluation). Funding provided, a follow-up will be conducted in 2025 and further years.

\section{Assignment method and eligibility}

The unit of assignment is the community, the assignment method is self-selection. Individual 1:1-matching (see below) was employed to help minimize potential bias induced due to non-randomization.

Sampling was initiated in April 2020 by inviting all German CTC-communities that would be in Phases 1 to 3 in the CTC cycle by January 2021. To be included in the trial, communities had to have at least one secondary school and willingness to sign a cooperative agreement for study participation with the principal investigator Hannover Medical School. This resulted in a final sample of 21 CTC-communities (16 small towns and five city districts) by July 2021 .

Immediately after a CTC-community was recruited, individual 1:1-matching was used to identify comparable communities in the same federal state. For this, a nearest-neighbor matching procedure was applied to community-level data from official statistics 2017 (www. inkar.de) and police crime statistics (PCS) 2019, using indicators of municipality type, community development (growth vs. stable vs. shrinkage), long-term unemployment, fiscal power, criminality, vandalism, drug use as well as shoplifting rate in youth. For each recruited CTC-community, the comparison community with the best-matching score was requested to participate in the
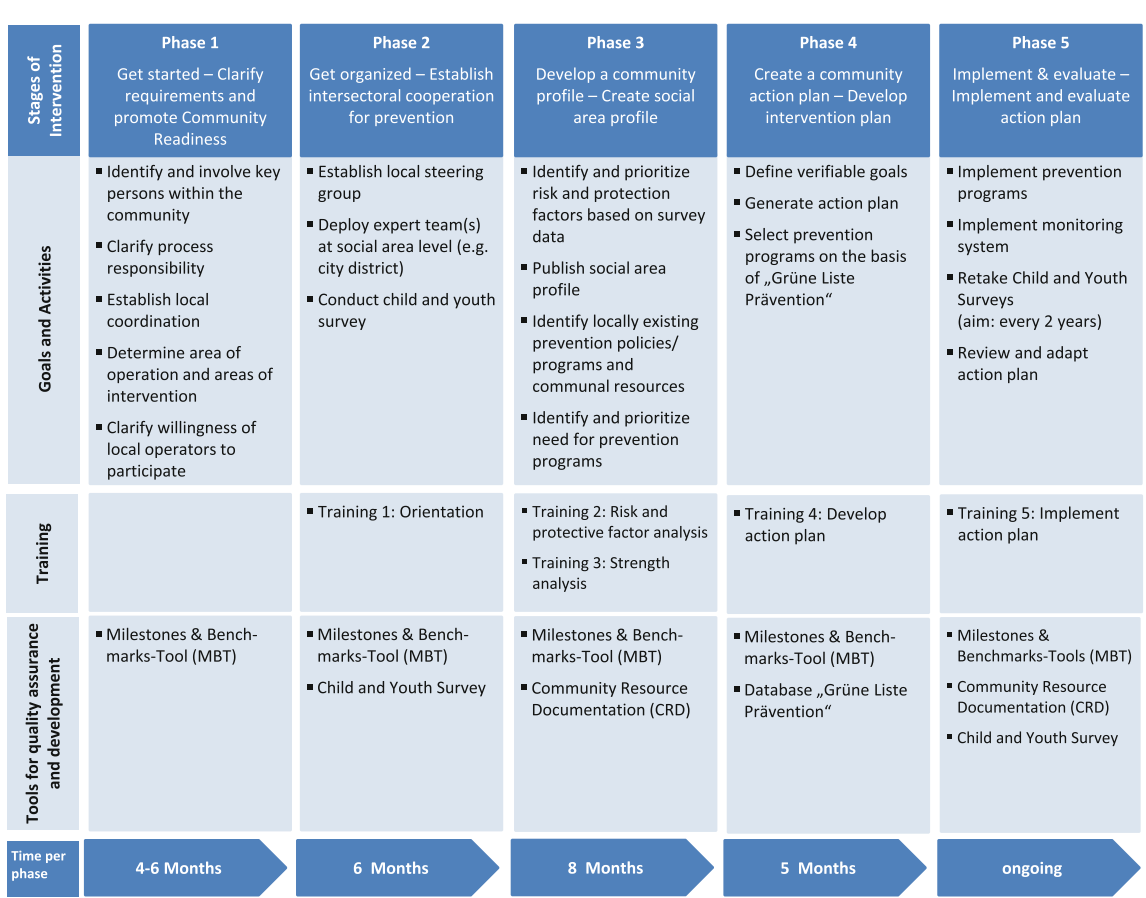

Fig. 2 Overview of phases and components of the intervention [cf. 6] 


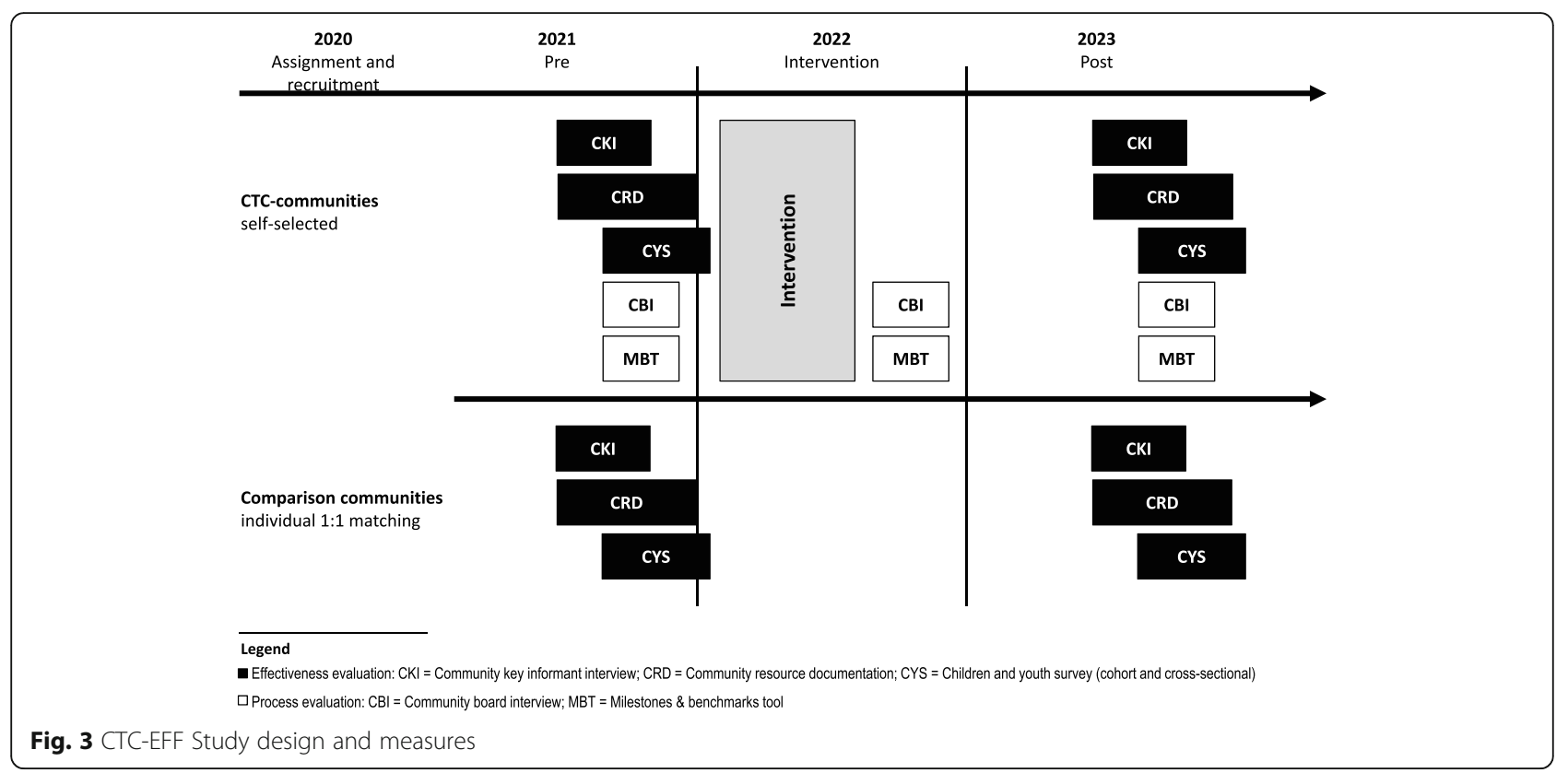

study. In case the community was not interested in participating, the next most similar community was contacted. Comparison communities were only eligible to participate in the study if (1) they had at least one secondary school, (2) they were not located in a county that implements CTC, (3) they were not directly adjacent to a CTC-community, and (5) they signed a cooperative agreement for study participation with the principal investigator Hannover Medical School. Overall, a sample of 21 matched pairs was recruited.

\section{Participants and eligibility \\ Community key informants}

In each study community, people in leadership positions (e.g., mayors, city managers, police chiefs, school superintendents, business leaders, heads of social service agencies) will be invited to participate. These leaderships will be identified via the research staff and by using a snowball sampling method. Only those persons who have consented to the data collection will be interviewed.

\section{Prevention actors}

Prevention actors (directors of community agencies and coalitions, prevention program coordinators and staff, school principals, teachers) who are responsible for prevention activities and programs in the study communities will be invited to participate. These actors will be identified via the research staff and by using a snowball sampling method. Only those persons who have consented to the data collection will be interviewed.

\section{Community board members}

All members of the local CTC-prevention networks (community boards) will be invited to participate. Only those persons who have consented to the data collection will be interviewed.

\section{CTC-trainers and local CTC-coordinators}

CTC trainers and local CTC coordinators are invited to participate and to consent to the data collection.

\section{Children and youth}

Every secondary school in the study communities and relevant schools in the vicinity of these communities attended by a substantial number of community adolescents will be invited to participate. The survey will depened on the support of (1) school principals and (2) class teachers. Additionally, written informed consent of the (3) parents will be mandatory. Finally, (5) each student will have to consent to the survey. For the cohort survey, students of Grade 5 will be invited to participate. For the cross-sectional survey, students of Grades 6, 8, 10,11 of secondary schools as well as students aged < 18 years of vocational schools are eligible.

\section{Measures \\ Effectiveness evaluation measures}

Community key informant interviews (CKI) A translated and adapted version of the CKI which was developed by Arthur, Glaser and Hawkins [33] will be conducted using computer-assisted telephone interviews. Data will be collected concerning (1) major changes or events in the community that could affect the local 
prevention activities; (2) the adoption of a science-based approach to prevention; (3) intersectoral collaboration for prevention; (5) community support for prevention; and (5) community norms against adolescent drug use.

Community resource documentation (CRD) A translated and modified version of the instrument set $[8,22]$ will be used to measure the type, number, and scope of prevention activities. Using computer-assisted telephone interviews, data will be collected concerning the names of all evidence-based programs that were conducted in the community, how many participants each program has reached and the fidelity of this program. Program fidelity will include the subcategories program adaptation, adherence, dosage, participant responsiveness and oversight and will be based on previous items measuring program fidelity within CTC-contexts (see [22, 34, 35]). Additionally, cost data of the prevention activities and programs will be collected.

Children and youth survey (CYS) A translated and adapted version of the US CTC survey [33], which was applied in Lower Saxony-wide surveys to establish reference values [36, 37], will be used to collect data on (1) socio-demographic variables (gender, age, parents living together, family size, language background, socioeconomic status); (2) self-reported problem areas (violence, delinquency, substance use, truancy/temporary school drop-out, depressive symptoms, mobbing, intimate partner violence, discriminatory behavior, life and health satisfaction); (3) risk factors (community, family, school, peer/individual); (5) protective factors (community, family, school, peer/individual); (5) COVID-19 questions based on the JuCo study [38]. Each survey will take about $45 \mathrm{~min}$ and will take place during a school lesson as an online survey. For schools unable to provide an internet connection or computers, a paper version of the questionnaire will be available.

\section{Process evaluation measures}

Community board interview (CBI) A translated and adapted version of the CBI will be used to monitor the implementation of CTC in the intervention communities. The CBI captures constructs associated with developing and maintaining an effective community coalition $[39,40]$. The construct community coalition capacity captures five components [39]: (1) members' substantive knowledge of prevention; (2) members' acquisition of new skills; (3) members' attitudes toward CTC; (4) organizational linkages to the coalition across community sectors; (5) and members' perceptions of their coalition's influence on organizations in the community on the development of intersectoral cooperation. The construct team functioning includes four components [40]: (1) goal directedness; (2) efficiency; (3) opportunities for participation; and (4) cohesion.

Milestones and benchmarks tool (MBT) Additional measures of CTC implementation are obtained from ratings of the CTC Milestones and Benchmarks (see [41]). The CTC training materials describe "milestones" and "benchmarks" that are to be achieved during the five phases of CTC system implementation. The milestones are goals to be met by communities, and the benchmarks are the actions that community members take or conditions that must be present to achieve those goals. The local CTC-coordinators and the CTC-trainers are asked to send their ratings annually to the research team of this study.

\section{Outcomes \\ Primary outcomes}

Primary short-term outcome Based on the CYDS [21], we hypothesize that, compared to comparison communities, CTC-communities will (1) have stronger improvements regarding the adoption of a science-based approach to preventing youth problem behaviour, (2) have stronger improvements in intersectoral collaboration for prevention, and (3) have stronger improvements in community support for prevention.

Primary long-term outcomes We hypothesize that CTC-communities will show lower prevalence and incidence of (1) antisocial behaviour and (2) substance use as well as (3) higher levels of well-being.

\section{Secondary outcomes}

Secondary short-term outcomes Based on the CYDS [34], we hypothesize that, compared to comparison communities, CTC-communities will (1) implement more evidence-based prevention programs, (2) reach more persons with the implemented prevention programs, and (3) conduct the prevention programs with a higher fidelity.

Secondary long-term outcomes We hypothesize that risk factors (community, family, school, peer/individual) which have been prioritized by the CTC-communities decrease whereas prioritized protective factors increase.

\section{Sample size calculation}

For sample size calculations https:// researchmethodsresources.nih.gov (Research Methods Resources: National Institutes of Health 2021) was used. 
Sample size calculations were conducted for the primary outcome in the short-term and long-term.

\section{Primary short-term outcome: adoption score of science- based prevention}

The calculation is for a net difference in a cohort study. We assume a type 1 error rate of $5 \%$, desired power of $95 \%$, correlation over time for the outcome variable of 0.6. A priori matching of the communities is considered with a correlation between matching factors and the outcome of 0.1 (individual level) and 0.2 (community level). Based on Brown et al. [21], regression adjustment for respondent characteristics is considered. An intraclass correlation coefficient (ICC) of 0.181 is assumed and for comparison communities a probability of 0.13 as well as for CTC-communities a probability of 0.34 of being in stage five of the adoption score (0-5) at post-test. Based on Muellmann et al. [42], 10 individuals (key informants) per cluster were considered. This results in a net sample size of 17 CTC-communities and 17 comparison communities with an average of 10 participants (key informants). Assuming a loss-to-follow-up of two matched pairs (four communities), a sample of 38 communities (19 matched pairs) and a total of 380 participants (key informants) is required.

\section{Primary long-term outcomes: well-being, antisocial behavior, substance use}

The sample sizes for the cohort and repeated crosssectional design were calculated separately though largely relying on the same assumptions. Considering the heterogenous effects of the CYDS at the different follow-up intervals [43-45], we assume small effects $(\mathrm{d}=.2)$ for our primary outcomes in both the cohort and repeated cross-sectional design. We assumed a type 1 error rate of $5 \%$, desired power of $80 \%, \mathrm{SD}=1$, no adjustment for covariates, intraclass correlation of 0.013 [46]. An a priori matching of the communities (see below) was also considered with a correlation between matching factors and the outcome of 0.1 (individual level) and 0.3 (cluster level). For the cohort design, the calculation was based on a net difference assuming an average number of 150 individuals per cluster (community) and a correlation over time for the outcome variable of 0.7 (individual level) and 0.6 (cluster-level). For the cross-sectional design, the calculation was based on a simple difference assuming an average number of 450 individuals per cluster (community). Both calculations result in a required sample of 14 communities $(7$ per condition). The overall sample of students required for the cohort survey is $n=2100$ and for the cross-sectional survey $n=6300$. Assuming a loss-to-follow-up of two matched pairs (four communities), this results in a sample of 18 communities ( 9 matched pairs).

\section{Statistical methods \\ Effectiveness evaluation}

Short-term outcomes Changes in primary short-term outcomes (i.e., adoption of science-based prevention) will be assessed by using a three-level hierarchical linear model (HLM) [47] and a cumulative probability model [48] to model changes in each of the outcomes as a function of survey year (at Level 1) nested within respondents (at Level 2), in turn, nested within communities (at Level 3).

Long-term outcomes Primary and secondary outcomes will be tested for differences between intervention and control by using either complex or multilevel structural equation models depending on the necessity to adjust for baseline differences between the student populations of the matched communities. Models will incorporate the nested data structure of students in classes/schools in communities in matched pairs. Additionally, baseline levels of the outcomes will be included in the cohort analysis. The primary analysis focuses on the effect of intervention group on the primary outcomes at the community level. As secondary analyses, hypothesized mediation and moderation paths and effects at school and individual level will be tested.

\section{Economic evaluation}

The primary short-term and long-term outcomes collected will serve as effect parameters for the costeffectiveness analysis. Cost has two parts: the quantitative measurement of resource use and the assignment of unit costs or prices [49]. The resource quantities associated with the implementation of the CTC process and prevention programs will be divided into personnel and material resources, which will both be recorded using additional modules of the CBI and CRD instruments. The time and material expenditure determined will be assessed in monetary terms using wage and price documentation.

Costs will be calculated for (1) CTC communities (including costs for the CTC process and prevention programs) and for (2) comparison communities (including costs for prevention programs) in relation to CTC communities. All analyses are carried out on three levels: (a) average costs per community, (b) average and median costs per resident, (c) average and median costs per youth. Because the size of the communities can differ significantly whereas some cost parameters (e.g., CTC coordinators salaries, need for training in the community, costs of purchasing program curricula) arise regardless of the number of residents and young people within a community, average intervention costs might be skewed by a few communities at extremes of the 
population distribution [25]. Therefore, the median will be calculated in addition to the mean, since this is a more robust measure against outliers. A linear regression with community size as an independent variable will be another way to take differences in population distribution into account.

In a first step the overall costs for prevention programs at the beginning and at the end of the study period will be compared for both described variants. The same analyses will be done, differentiated in financial resources spent for evidence-based and non-evidencebased programs. In addition, we will determine the share that individual cost parameters have in the total costs for the CTC process.

In the cost-effectiveness analysis, the ascertained incremental costs for the CTC process and implementation of prevention programs will be compared with the incremental effectiveness of the CTC communities (compared to the comparison communities). The adoption of science-based prevention serves as the primary effect parameter in the short-term and positive youth outcomes (Fig. 1) will be evaluated as primary effect parameters in the long-term (funding provided). Calculation of confidence intervals and bootstrapping will be used to map the uncertainties in determining the costs and the incremental cost-effectiveness. If there is follow-up funding after 2023, it is planned to model the long-term effects (e.g., secondary diseases) and the long-term benefits (quality of life, life expectancy and monetary benefits) of the implementation of CTC.

\section{Discussion}

This is the first community trial to evaluate the effectiveness of a comprehensive community prevention approach in Germany. We expect that CTC will be associated with significant effects on risk and protective factors (secondary long-term outcomes) as well as student behaviour and well-being (primary long-term outcomes) through the adoption of a science-based approach of community prevention (primary short-term outcome) and the number of implemented evidencebased prevention programs and reached persons. While the evaluation of short-term outcomes can be conducted during the currently funded study period (April 2020 to December 2023), the evaluation of long-term outcomes is dependent on the study receiving follow-up funding of at least 2 years (see Fig. 1).

\footnotetext{
Abbreviations

CBI: Community Board Members Interview; CKI: Community Key Informants Interview; COVID-19: Corona Virus Disease 2019; CRD: Community Resource Documentation; CTC: Communities That Care; CTC-EFF: Effectiveness of the community preventions system Communities That Care; CYDS: Community Youth Development Study; CYS: Children and Youth Survey; d: Cohen's d; Fig.: Figure; MBT: Milestones and Benchmarks Tool; SD: Standard Deviation; U.S.: United States; WHO: World Health Organization
}

\section{Acknowledgements}

We would like to acknowledge the former and actual members of the Social Development Research Group at the University of Washington and especially Sabrina Oesterle, Arizona State University, for their advice in conducting the study and John Briney as well as Danielle Woodward, University of Washington, for providing the survey instruments and other materials from the Community Youth Development Study. We would also like to acknowledge Harrie B Jonkman, Verwey-Jonker Institute, Netherlands, for supporting our study. We acknowledge support by the German Research Foundation (DFG) and the Open Access Publication Fund of Hannover Medical School (MHH).

\section{Authors' contributions}

$D R$, UW, FGR, and RS were involved in developing the conception and design of the work. VB was responsible for writing the first draft of the manuscript. All authors read, critically revised, and approved the final manuscript. All authors agreed both to be personally accountable for the author's own contributions and to ensure that questions related to the accuracy or integrity of any part of the work, even ones in which the author was not personally involved, are appropriately investigated, resolved, and the resolution documented in the literature.

\section{Funding}

The Federal Ministry of Education and Research (BMBF) supported the current project (funding numbers: 01EL2006A and 01EL2006B). None of the funders were involved in the design of the study, manuscript writing or collection of data, and the funders will not be involved in data analysis or interpretation and manuscript writing in the future. Open Access funding enabled and organized by Projekt DEAL.

\section{Availability of data and materials}

Data sharing is not applicable to this article as no datasets were generated or analyzed during the current study.

\section{Declarations}

\section{Ethics approval and consent to participate}

This study was approved by the Hannover Medical School's and University of Hildesheim's ethics committee. There are no predetermined criteria for discontinuing or modifying the trial. No anticipated adverse consequences are anticipated for trial participants. In accordance with the ethics approval for the project, any protocol modification will be referred to the Hannover Medical School's ethics committee. All participating communities completed an informed consenting process with a member of the research team. Participation in the Youth Survey requires written consent from the parents and students. In the cross-sectional and longitudinal survey no personal information from students will be requested. Prior to the longitudinal survey, we will collect personal data on students and parents that will be stored separately from the survey data. The raw data sets obtained from the surveys are subjected to a quality control after completion of the individual survey waves and any necessary adjustments are made. The raw data sets and the quality-controlled data sets are stored. Analysis datasets are created from the quality-controlled datasets. Thus, the analysis datasets contain pseudonymised longitudinal data. Cross-sectional datasets are factually anonymous. Results of the prospective analyses will only be published on an aggregated level. A data monitoring committee is not needed for the purposes of this study given that authors are not blinded, and that the overall risk for harm is low. Absolutely anonymised datasets will be published at the end of the study in the Data Archive for Social Sciences.

\section{Consent for publication}

Not applicable.

\section{Competing interests}

The authors declare that they have no competing interests.

\section{Author details}

'Hannover Medical School, Institute for Epidemiology, Social Medicine and Health Systems Research, Hannover, Germany. ${ }^{2}$ University of Hildesheim, Institute for Psychology, Hildesheim, Germany. ${ }^{3}$ Crime Prevention Council of Lower Saxony, Hannover, Germany. 


\section{Received: 29 September 2021 Accepted: 7 October 2021} Published online: 23 October 2021

\section{References}

1. Pardis AD, Koenen KC, Fitzmaurice GM, Buka SL. Impact of persistent and adolescent-limited antisocial behaviour on adult health outcomes. J Epidemiol Community Health. 2016;70(10):1004-10. https://doi.org/10.1136/ jech-2014-205140

2. GBD 2017 Risk Factor Collaborators. Global, regional, and national comparative risk assessment of 84 behavioural, environmental and occupational, and metabolic risks or clusters of risks for 195 countries and territories, 1990-2017: a systematic analysis for the Global Burden of Disease Study 2017. Lancet. 2018:392(10159):1923-94.

3. Lanctôt N, Cernkovich SA, Giordano PC. Delinquent behavior, official delinquency, and gender: consequences for adulthood functioning and well-being. Criminology. 2007;45(1):131-57. https://doi.org/10.1111/j.17459125.2007.00074.x

4. WHO (World Health Organization). Alcohol and cancer in the WHO European Region: An appeal for better prevention [Internet]. Copenhagen: WHO Regional Office for Europe; 2020. [cited 2021 abbrev. 08.12]. Available from WHO-EURO-2020-1435-41185-56004-eng.pdf

5. Santos L, De Oliveira MF, Amann VR, Schäfer AA. Temporal trends in behavioural risk and protective factors and their association with mortality rates: results from Brazil and Argentina. BMC Public Health. 2020;20(1):1390. https://doi.org/10.1186/s12889-020-09512-9 .

6. Forouzanfar MH, Afshin A, Alexander LT, Anderson HR, Bhutta ZA, Biryukov S. Global, regional, and national comparative risk assessment of 79 behavioural, environmental and occupational, and metabolic risks or clusters of risks, 1990-2015: a systematic analysis for the global burden of disease study 2015. Lancet. 2016;388(10053):1659-724. https://doi.org/10.101 6/S0140-6736(16)31679-8

7. NIDA. Community-monitoring systems. In: Tracking and improving the wellbeing of America's children and adolescents: National Institute on Drug Abuse website [Internet]; 2007. [cited 2021 abbrev. 08.12]. Available from: https://archives.drugabuse.gov/publications/community-monitoringsystems-tracking-improving-well-being-americas-children-adolescents.

8. Hawkins JD, Catalano RF, Arthur MW, Egan E, Brown EC, Abbott RD, et al. Testing communities that care: the rationale, design and behavioural baseline equivalence of the community youth development study. Prev Sci. 2008;9(3):178-90. https://doi.org/10.1007/s11121-008-0092-y .

9. Odugleh-Kolev A, Parrish-Sprowl J. Universal health coverage and community engagement. Bull World Health Organ. 2018;96(9):660-1. https://doi.org/10.2471/BLT.17.202382

10. Yuan $M$, Lin H, Wu H, Yu M, Tu J, Lü Y. Community engagement in public health: a bibliometric mapping of global research. Arch Public Health. 2021; 79(1):6. https://doi.org/10.1186/s13690-021-00525-3 .

11. Barreto ML. Efficacy, effectiveness, and the evaluation of public health interventions. J Epidemiol Community Health. 2005;59(5):345-6. https://doi. org/10.1136/jech.2004.020784 .

12. Layde PM, Christiansen AL, Peterson DJ, Guse CE, Maurana CA, Brandenburg T. A model to translate evidence-based interventions into community practice. Am J Public Health. 2012;102(4):617-24. https://doi.org/10.2105/A JPH.2011.300468

13. Gottfredson DC, Gottfredson GD. Quality of school-based prevention programs: results from a national survey. J Res Crime Delinq. 2002;39(1):335. https://doi.org/10.1177/002242780203900101

14. Durlak JA, DuPre EP. Implementation matters: a review of research on the influence of implementation on program outcomes and the factors affecting implementation. Am J Community Psychol. 2008;41(3-4):327-50. https://doi.org/10.1007/s10464-008-9165-0 .

15. Maitland N, Wardle K, Whelan J, Jalaludin B, Creighton D, Johnstone M, et al. Tracking implementation within a community-led whole of system approach to address childhood overweight and obesity in south West Sydney, Australia. BMC Public Health. 2021;21(1):1233. https://doi.org/10.11 86/s12889-021-11288-5.

16. Bagnall AM, Radley D, Jones R, Gately P, Nobles J, Van Dijk M. Whole systems approaches to obesity and other complex public health challenges: a systematic review. BMC Public Health. 2019;19(1):8. https://doi.org/10.11 86/s12889-018-6274-z
17. Wandersman A. Community science: bridging the gap between science and practice with community-centered models. Am J Community Psychol. 2003;31(3-4):227-42. https://doi.org/10.1023/A:1023954503247.

18. Cyril S, Smith BJ, Possamai-Inesedy A, Renzaho AM. Exploring the role of community engagement in improving the health of disadvantaged populations: a systematic review. Glob Health Action. 2015;82(1):29842. https://doi.org/10.3402/gha.v8.29842.

19. O'Mara-Eves A, Brunton G, Oliver S, Kavanagh J, Jamal F, Thomas J. The effectiveness of community engagement in public health interventions for disadvantaged groups: a meta-analysis. BMC Public Health. 2015;15(1):129. https://doi.org/10.1186/s12889-015-1352-y.

20. Bagnall AM, Radley D, Jones R, Gately P, Nobles J, van Dijk M, et al. Whole systems approaches to obesity and other complex public health challenges: a systematic review. BMC Public Health. 2019;19(1):8. https://doi.org/10.11 86/s12889-018-6274-z

21. Brown EC, Hawkins JD, Arthur MW, Briney JS, Abbott RD. Effects of communities that care on prevention services systems: findings from the community youth development study at 1.5 years. Prev Sci. 2007;8(3):18091. https://doi.org/10.1007/s11121-007-0068-3.

22. Fagan AA, Hanson K, Briney JS, Hawkins JD. Sustaining the utilization and high quality implementation of tested and effective prevention programs using the communities that care prevention system. Am J Community Psychol. 2012;49(3-4):365-77. https://doi.org/10.1007/s10464-011-9463-9.

23. Hawkins JD, Oesterle S, Brown EC, Arthur MW, Abbott RD, Fagan AA, et al. Results of a type 2 translational research trial to prevent adolescent drug use and delinquency: a test of communities that care. Arch Pediatr Adolesc Med. 2009;163(9):789-98. https://doi.org/10.1001/a rchpediatrics.2009.141.

24. Brown EC, Hawkins JD, Rhew IC, Shapiro VB, Abbott RD, Oesterle S, et al. Prevention system mediation of communities that care effects on youth outcomes. Prev Sci. 2014;15(5):623-32. https://doi.org/10.1007/s11121-0130413-7.

25. Kuklinski MR, Briney JS, Hawkins JD, Catalano RF. Cost-benefit analysis of communities that care outcomes at eighth grade. Prev Sci. 2012;13(2):15061. https://doi.org/10.1007/s11121-011-0259-9.

26. Groeger-Roth F. Prävention von psychischen Störungen auf kommunaler Ebene: Zur Umsetzung von Communities That Care - CTC in Deutschland. In: Christiansen H, Ebert D, Röhrle B, editors. Prävention und Gesundheitsförderung Bd, VI: Entwicklungen und Perspektiven. 1st ed. Tübingen: dgtv-Verlag; 2018. p. 177-94.

27. Schubert $H$, Veil K, Spieckermann H, Abels S. Evaluation des Modellprogramms "Communities That Care" in Niedersachsen. Theoretische Grundlagen und empirische Befunde zur sozialräumlichen Prävention in Netzwerken. Köln: Verlag Sozial Raum Management; 2013.

28. Beumer $\mathrm{M}$, Jonkman $\mathrm{H}$, Vergeer M. Das CTC-Handbuch. Arbeiten mit Communities That Care. 2nd ed. Hannover: Landespräventionsrat Niedersachsen; 2013.

29. Nutbeam D. Health promotion glossary. Health Promot Int. 1998;13(4)

30. WHO (World Health Organization). Ottawa Charter for Health Promotion, 1986 [Internet]. [cited 2021 abbrev. 08.12]. Available from https://www.euro. who.int/de/publications/policy-documents/ottawa-charter-for-healthpromotion,-1986.

31. Böhm K, Gehne D. Vernetzte kommunale Gesundheitsförderung für Kinder und Jugendliche. Überblick über den Status quo in Deutschland. Bundesgesundheitsbl. 2018;61(1):1214. https://doi.org/10.1007/s00103-018-2 803-2.

32. Reeves $B C$, Wells GA, Waddington $H$. Quasi-experimental study designs series-paper 5: a checklist for classifying studies evaluating the effects on health interventions-a taxonomy without labels. J Clin Epidemiol. 2017;89: 30-42. https://doi.org/10.1016/j.jclinepi.2017.02.016.

33. Arthur MW, Glaser RR, Hawkins JD. Steps toward community-level resilience In: Peters RD, Leadbeater B, McMahon RJ, editors. Resilience in children, families, and communities. Boston: Springer; 2005. https://doi.org/10.1007/ 0-387-23824-7_11.

34. Fagan AA, Hanson K, Hawkins JD, Arthur MW. Bridging science to practice: achieving prevention program implementation fidelity in the community youth development study. Am J Community Psychol. 2008;41(3-4):235-49. https://doi.org/10.1007/s10464-008-9176-x.

35. Fagan AA, Arthur MW, Hanson K, Briney JS, Hawkins JD. Effects of communities that care on the adoption and implementation fidelity of evidence-based prevention programs in communities: results from a 
randomized controlled trial. Prev Sci. 2011;12(3):223-34. https://doi.org/10.1 007/s11121-011-0226-5.

36. Soellner R, Frisch JU, Reder M. Communities That Care: Schülerbefragung in Niedersachsen 2015. Hildesheim: Universität Hildesheim; 2016.

37. Soellner R, Reder M, Frisch JU. Communities That Care: Schülerbefragung in Niedersachsen 2017. Hildesheim: Universität Hildesheim; 2018.

38. Wilmes J, Lips A, Heyer L. Datenhandbuch zur bundesweiten Studie JuCo. Hildesheim: Universitätsverlag Hildesheim; 2020.

39. Shapiro VB, Oesterle S, Hawkins JD. Relating coalition capacity to the adoption of science-based prevention in communities: evidence from a randomized trial of communities that care. Am J Community Psychol. 2015; 55(1-2):1-12. https://doi.org/10.1007/s10464-014-9684-9.

40. Shapiro VB, Hawkins JD, Oesterle S. Building local infrastructure for community adoption of science-based prevention: the role of coalition functioning. Prev Sci. 2015;16(8):1136-46. https://doi.org/10.1007/s11121-01 5-0562-y.

41. Quinby RK, Hanson K, Brooke-Weiss B, Arthur MW, Hawkins JD. Installing the communities that care prevention system: implementation progress and fidelity in a randomized controlled trial. J Community Psychol. 2008;36(3): 313-32. https://doi.org/10.1002/jcop.20194.

42. Muellmann S., Brand T, Jürgens D. How many key informants are enough? Analysing the validity of the community readiness assessment. BMC Res Notes 2021;85(14). https://doi.org/10.1186/s13104-021-05497-9.

43. Hawkins JD, Oesterle S, Brown EC, Monahan KC, Abbott RD, Arthur MW, et al. Sustained decreases in risk exposure and youth problem behaviors after installation of the communities that care prevention system in a randomized trial. Arch Pediatr Adolesc Med. 2012;166(2):141-8. https://doi, org/10.1001/archpediatrics.2011.183

44. Hawkins JD, Brown EC, Oesterle S, Arthur MW, Abbott RD, Catalano RF. Early effects of communities that care on targeted risks and initiation of delinquent behavior and substance use. J Adolesc Health. 2008;43(1):15-22. https://doi.org/10.1016/j.jadohealth.2008.01.022.

45. Rhew IC, Hawkins JD, Murray DM, Fagan AA, Oesterle S, Abbott RD, et al. Evaluation of community-level effects of communities that care on adolescent drug use and delinquency using a repeated cross-sectional design. Prev Sci. 2016;17(2):177-87. https://doi.org/10.1007/s11121-0150613-4.

46. Brown EC, Graham JW, Hawkins JD, Arthur MW, Baldwin MM, Oesterle S. Design and analysis of the community youth development study longitudinal cohort sample. Eval Rev. 2009;33(4):311-34. https://doi.org/1 $0.1177 / 0193841 \times 09337356$

47. Raudenbush SW, Bryk AS. Hierarchical linear models: applications and data analysis methods. 2nd ed. Newbury Park, CA: Sage; 2002.

48. Raudenbush SW, Bryk S, Cheong YF, Congdon R. HLM6: hierarchical linear and nonlinear modeling. Chicago: Scientific Software International; 2004.

49. Drummond MF, Sculpher MJ, Torrance GW, O'Brien J, Stoddart GL. Methods for the economic evaluation of health care programs. 3rd ed. Oxford: Oxford University Press; 2005

\section{Publisher's Note}

Springer Nature remains neutral with regard to jurisdictional claims in published maps and institutional affiliations.

Ready to submit your research? Choose BMC and benefit from:

- fast, convenient online submission

- thorough peer review by experienced researchers in your field

- rapid publication on acceptance

- support for research data, including large and complex data types

- gold Open Access which fosters wider collaboration and increased citations

- maximum visibility for your research: over $100 \mathrm{M}$ website views per year

At $\mathrm{BMC}$, research is always in progress.

Learn more biomedcentral.com/submissions 